LAWRENCE LIVERMORE NATIONAL LABORATORY

\title{
A Graphical Big Picture for Tank Technologies
}

John C. Whitehead, LLNL

Dan Moser, Compositex Inc.

\section{July 8, 2007}

$43^{\text {rd }}$ AIAA/ASME/SAE/ASEE

Joint Propulsion Conference and Exhibit

Cincinnati, $\mathrm{OH}$

Paper Number AIAA-2007-5494

AIAA = American Institute of Aeronautics and Astronautics

ASME = American Society of Mechanical Engineers

SAE = Society of Automotive Engineers

ASEE = American Society of Engineering Education 
This document was prepared as an account of work sponsored by an agency of the United States Government. Neither the United States Government nor the University of California nor any of their employees, makes any warranty, express or implied, or assumes any legal liability or responsibility for the accuracy, completeness, or usefulness of any information, apparatus, product, or process disclosed, or represents that its use would not infringe privately owned rights. Reference herein to any specific commercial product, process, or service by trade name, trademark, manufacturer, or otherwise, does not necessarily constitute or imply its endorsement, recommendation, or favoring by the United States Government or the University of California. The views and opinions of authors expressed herein do not necessarily state or reflect those of the United States Government or the University of California, and shall not be used for advertising or product endorsement purposes. 


\author{
John C. Whitehead ${ }^{*}$ \\ Lawrence Livermore National Laboratory, Livermore, CA 94551 \\ Daniel J. Moser ${ }^{\dagger}$ \\ Compositex Inc., Sandy, UT 84092
}

\begin{abstract}
A graphical method is presented for comparing different tank technologies and evaluating scalability, over wide ranges of volume and pressure. Mass contours are plotted on log-log graphs of pressure versus volume, using either theory or data points representing hardware. The simple theoretical case for infinitely scaleable tanks made of a single isotropic material has a constant value of $\mathrm{PV} / \mathrm{m}$ over the entire plot, and results in straight diagonal mass contours. The contours become more complicated as a result of practical considerations. The latter include minimum wall thickness limits and non-pressure structrual loads, as well as minimum thicknesses for the liner and composite over-wrap of multi-layered tank walls. Given a requirement for a tank at a particular volume and pressure, a set of plots representing different technologies can be used to estimate tank masses and select one or more technologies that would meet the need.
\end{abstract}

\title{
I. Introduction
}

High performance aerospace vessels are used to contain liquids and gases, typically propellants or pressurant on the way to orbit or in space. A traditional and widely-used measure of performance is PV/m, the ratio of a tank's pressure-volume product to its mass. This figure of merit is essentially a combined measure of material capability, vessel shape, and quality of construction. $\mathrm{PV} / \mathrm{m}$ is theoretically independent of both size and pressure for a given tank technology, because the ideal wall thickness scales as pressure and tank diameter. Figure 1 shows equations that apply to a spherical shell having thin walls $(\mathrm{t}<<\mathrm{r})$ loaded only by internal pressure. Combining the first three equations leads to the fourth one. Note that the achievable value of $\mathrm{PV} / \mathrm{m}$ is simply proportional to the ratio of material stress to material density. The constant of proportionality depends on the shape of the tank, e.g. $2 / 3$ for

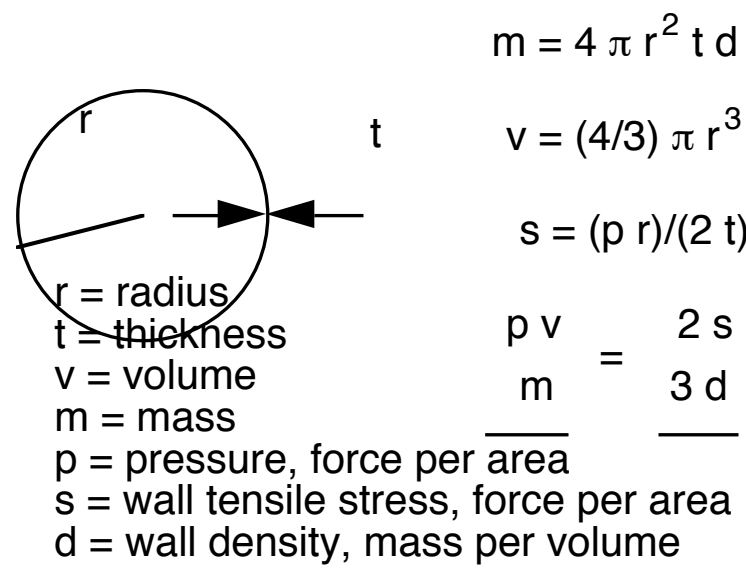

Fig. 1. Ideal relations for spherical tanks. spheres as shown in Fig. 1, and 1/2 for long cylinders.

In practice, $\mathrm{PV} / \mathrm{m}$ depends on size due to minimum wall thickness limitations. $\mathrm{PV} / \mathrm{m}$ also varies with pressure because walls that must be thick, relative to diameter, do not carry tensile stress uniformly through their thickness. Non-pressure loads and fluid ports require extra structural mass, which reduces the net value of $\mathrm{PV} / \mathrm{m}$ for real tanks.

As a result of all the non-ideal effects, the traditional performance measure, $\mathrm{PV} / \mathrm{m}$, is not sufficient to characterize a particular tank technology over a broad range of size and pressure. Advances in composite over-wrapped pressure vessel (COPV) technology during recent decades have pushed aerospace tank performance beyond traditional capability. Increased complexity of tank construction leads to further departures from theoretical scalability.

* PO Box 808, Mail Stop L-072, AIAA Senior Member.

$₫ 11815$ Littler Road, AIAA Senior Member. 


\section{Graphing the Big Picture}

This paper introduces a way to graph pressure, volume, and mass to represent the capabilities of a particular tank technology over a wide range, and the non-ideal effects can be included to whatever extent is desired. Volume and pressure are represented by logarithmic scales, as shown in Fig. 2. Contours of constant tank mass are then plotted. Figure 2 in particular represents spherical titanium tanks, at a hoop stress of $655 \mathrm{MPa}(95 \mathrm{ksi})$. The only nonideality included in this example is that the minimum wall thickness was set to $0.25 \mathrm{~mm}(0.010 \mathrm{in})$, regardless of tank diameter. A dashed line represents the borderline of the minimum wall thickness region. Its slope is $-1 / 3$, because pressure varies inversely as the cube root of volume at constant wall thickness. Above the borderline, the value of $\mathrm{PV} / \mathrm{m}$ is $10^{5} \mathrm{~N}-\mathrm{m} / \mathrm{kg}(\mathrm{PV} / \mathrm{W}=400 \mathrm{k}$ inch), over all values of pressure and volume. Everywhere below the borderline, the wall thickness is constant while $\mathrm{PV} / \mathrm{m}$ varies greatly.

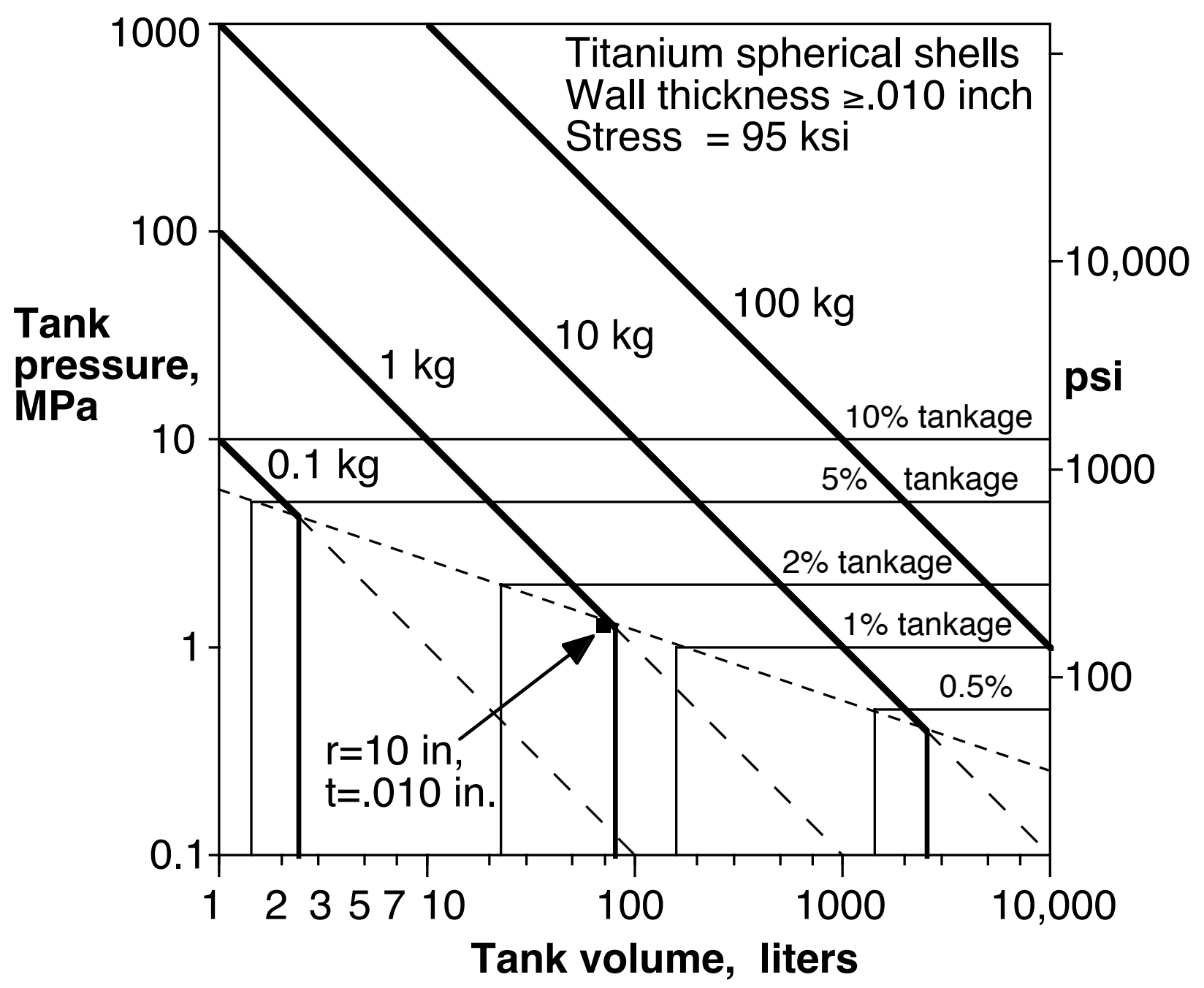

Fig. 2. A "big picture" plot for pressurized titanium spherical shells.

The diagonal mass contours bend and become vertical, because the pressure requirement no longer influences the tank design when the minimum wall thickness is reached. In the absence of a lower limit on thickness, the mass contours would continue straight along the diagonal dashed lines. An additional set of contours is plotted in Fig. 2, to indicate the ratio of tank mass to volume, or more specifically the contained mass of a fluid having the density of water. In general, launch vehicles use low-pressure 1-percent tankage, ${ }^{1}$ while satellite liquid tanks have masses in the range 3 percent to 10 percent of contained propellants, depending on size. 
The same two sets of contours can be plotted for any tank technology, with all real effects considered, in order to quickly view what is possible over a range of tank volume and tank pressure. The effects of extreme pressures and volumes, both high and low, become readily apparent in such a plot.

A set of graphs representing different technologies would be a useful tool during preliminary design of propulsion systems. Given the need for a tank having a required volume and a particular pressure, the resulting tank masses could be quickly estimated and compared among applicable technologies.

\section{Big Picture Plots for Composite Over-Wrapped Pressure Vessels}

Compositex Inc. numerical design methods were used to generate a family of curves representing generic aluminum-lined composite over-wrapped pressure vessels (COPV's). Figure 3 is intended to illustrate the significant differences from the all-metal tanks represented in Fig. 2. The simplified assumptions leading to Fig. 3

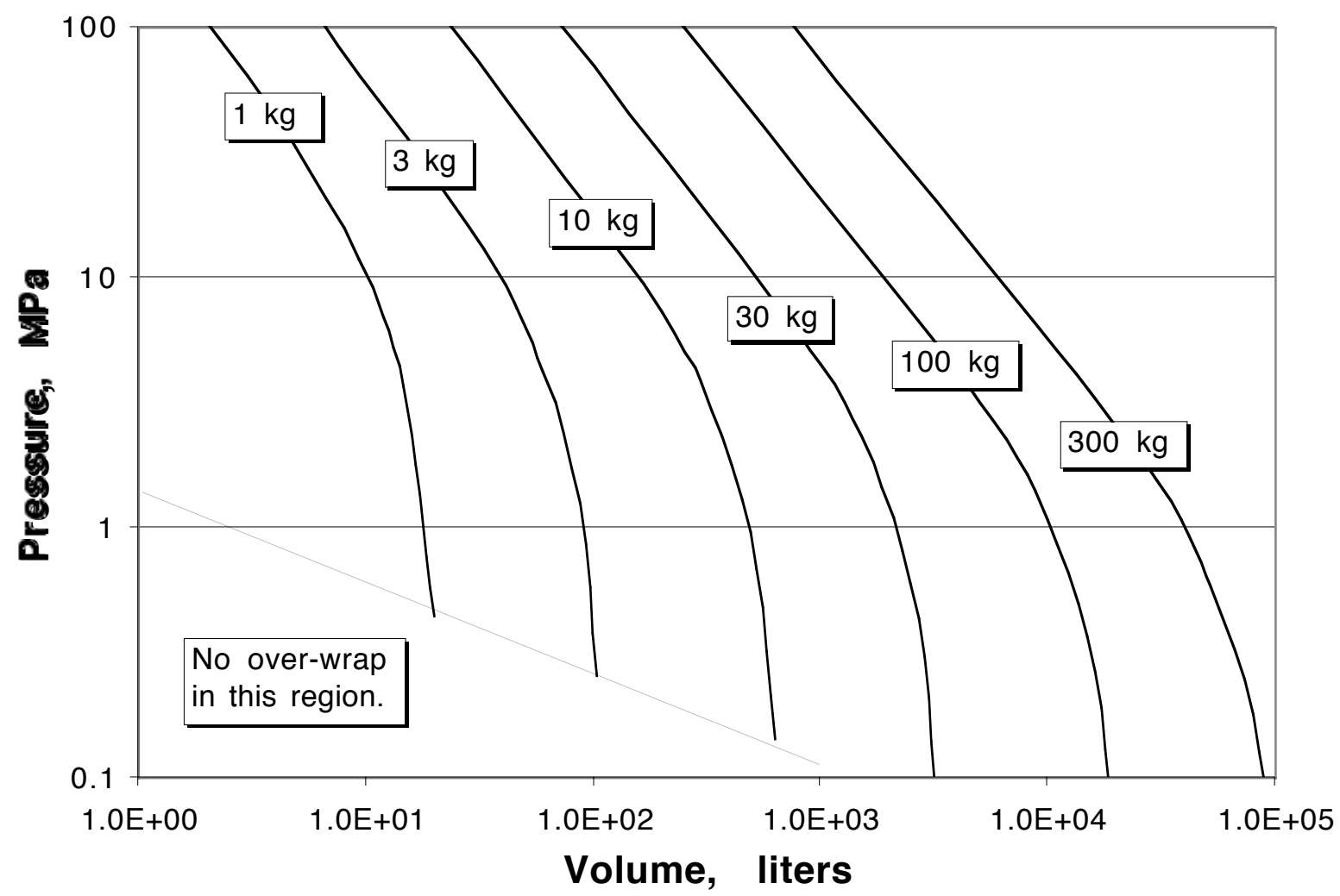

Fig. 3. A "big picture" plot for aluminum-lined composite over-wrapped pressure vessels (COPV's).

include a 0.6-mm liner thickness regardless of tank size, and the mass of fluid ports (bosses) is neglected. The overall length to diameter ratio is 3.0 in all cases, and end dome height is 0.7 times the tank radius. Fiber strength is $5.5 \mathrm{Gpa}(800 \mathrm{ksi})$, and the tank safety factor is 2.0 .

The aluminum liner is assumed to carry a $138 \mathrm{MPa}(20 \mathrm{ksi})$ operating tensile stress throughout Fig. 3 . In the triangular region at low pressures and volumes, there is no composite over-wrap because the aluminum alone is sufficient to carry the pressure load. While the mass contours in Fig. 2 have a discontinuity in their slope, those in Fig. 3 curve gradually toward vertical as pressure falls. The reason is that the relative load sharing between liner and over-wrap changes smoothly as the composite thickness decreases. It should be noted, however, that the curves shown here were generated without a restriction on minimum over-wrap thickness.

The following two examples are indicative of the fact that no single technology would be preferred for all pressures and volumes. At 1000 liters and $10 \mathrm{MPa}$, Fig. 2 shows that the mass of a titanium tank would be $100 \mathrm{~kg}$, while a $\sim 55-\mathrm{kg}$ COPV per Fig. 3 would be preferred. However, at $1 \mathrm{MPa}$, the graphs show that a COPV is heavier than a titanium tank (17 kg vs $10 \mathrm{~kg})$, based on the stated assumptions. Although both graphs represent 
simplifications relative to real tanks, it is clear that such comparisons can offer insight into tank selection for a particular pressure and volume.

Figure 4 illustrates the use of the method to represent real hardware. Points are plotted for a number of state-ofthe-art tanks that are offered for sale by multiple suppliers, intended for spacecraft and launch vehicle applications. The estimated 10-kg mass contour in Fig. 4 coincides approximately with its counterpart in Fig. 3. Not surprisingly, no COPV tanks are routinely offered for sale in the region of zero over-wrap thickness.

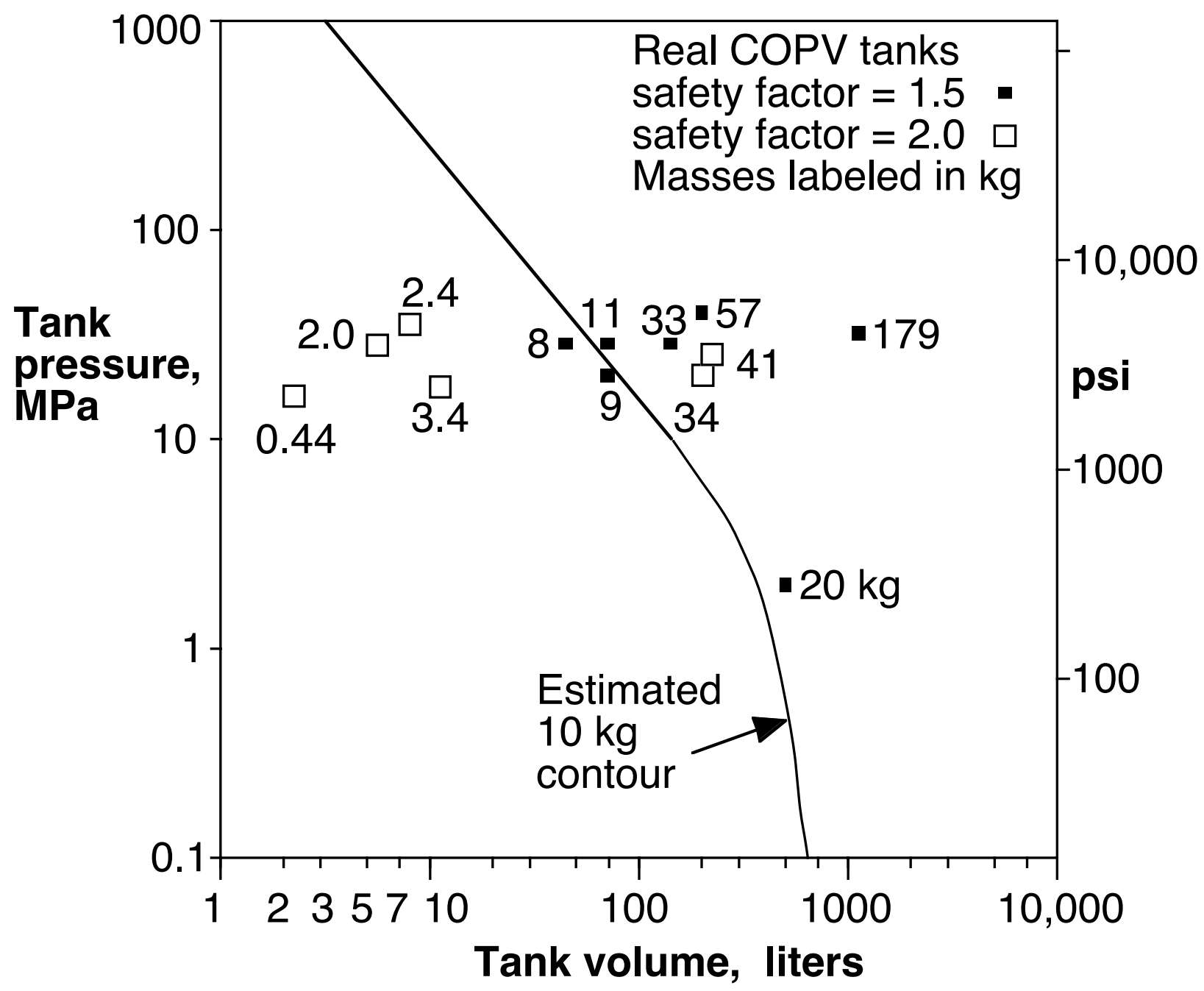

Fig. 4. A scatter plot representing real composite tanks sold for spacecraft and launch vehicle applications.

Specialized development efforts have been undertaken to implement lightweight COPV's for low pressure applications, i.e. spacecraft liquid tanks. ${ }^{2}$ The challenge has been to reduce the thickness of both the liner and overwrap. Such advances at the limits of capability have reduced the usefulness of PV/m by itself in understanding and comparing achievable tank performance. The graphical method described in this paper would be particularly useful for characterizing any new tank technology, and interpreting its applicability as a function of pressure and volume.

\section{Conclusion}

This paper has presented a graphical method for viewing the performance and application limits of individual pressure vessel and tank technologies over a wide range of sizes and pressures. Contours of constant mass, plotted on a log-log graph of pressure versus volume, can present a complete single picture for a given set of design 
assumptions. Proven hardware, such as a family of flight-qualified tanks, can also be used to generate mass contours in order to quickly predict the mass of a similar tank that needs to be sized for a new requirement.

While the traditional means of comparing pressure vessel technologies, $\mathrm{PV} / \mathrm{m}$, has limited relevance at the extremes of pressure and volume, the graphical method offered here can incorporate any and all non-ideal effects. The latter include minimum wall thickness limits, liner thickness limits for multi-layer walls, and minimum overwrap thickness. At very high pressures, the reduced performance of thick-walled pressure vessels can also be depicted. In addition, extra mass required to accommodate fluid port connections and non-pressure loads can be included in order to represent flight tanks as realistically as possible.

\section{Acknowledgment}

This work was performed under the auspices of the U.S. Department of Energy, by the University of California, Lawrence Livermore National Laboratory under Contract W-7405-Eng-48.

\section{References}

${ }^{1}$ Whitehead, J.C., "Mass Breakdown of the Saturn V," AIAA Paper 2000-3141, July 2000.

${ }^{2}$ Lewis, J.., Grimes-Ledesma, L., Essandoh, V., Harris, J., Cain, S., and Bishop-Behal, K., "Development of Ultralight Composite-Overwrapped Propellant Tanks," JANNAF Second Liquid Propulsion Subcommittee/First Spacecraft Propulsion Subcommittee Joint Meeting Proceedings, Monterey, Calif., December 2005, Chemical Propulsion Information Analysis Center (CPIAC) JSC CD-43. 